\title{
Desinstitucionalización o abandono de la política
}

Deinstitutionalization or Abandonment of Politics

Gerardo de la Fuente Lora

Universidad Nacional Autónoma de México delafuentelora@gmail.com

DOI: http://doi.org/10.15366/bp2019.20.002 Bajo Palabra. II Época. No20. Pgs: 39-50 


\section{Resumen}

Desde los comienzos de la modernidad, los discursos que han logrado seducir a la sociedad, a las personas y a los movimientos sociales, son aquellos que han enarbolado la propuesta de poner fin a la política. Tanto el liberalismo como el marxismo tuvieron en común esa perspectiva: ambos fueron formas de utopías que soñaron con la eliminación de la política como componente del mundo social. La desinstitucionalización, es decir, la inefectividad de toda acción que hoy se pretenda política, es la forma que ha asumido en nuestros días el viejo ideal de terminar con la política. En cierto sentido se trata de la utopía realizada.

Palabras Clave: Desinstitucionalización, Politica, Gobierno, Administración de expectativas

\section{Abstract}

From the beginning of modernity, the speeches that have managed to seduce society, people and social movements, are those that have raised the proposal to end politics. Both liberalism and Marxism had this perspective in common: both were forms of utopias that dreamed of the elimination of politics as a component of the social world. The deinstitutionalization, that is to say, the ineffectiveness of any action that today is intended as a policy, is the form that the old ideal of ending politics has assumed in our days. In a certain sense it is the realized utopia.

Keywords: Deinstitutionalization, Politics, Government, Management of expectations 
LA DESINSTITUCIONALIZACión ES EL CAMino en que han confluido ahora liberalismo y marxismo en su afán de terminar con la política. Por una vía peculiar, pues no se trata tanto de acabar con ella, como de cancelar cualquier acceso real, eficaz, a la misma

Todo discurso que en la modernidad haya sido capaz de interpelar mínimamente a alguien, producir algún efecto en la realidad, existir al menos por un momento en la opinión pública y en los sueños personales de alguien, ha recurrido para ello, para su encantamiento, a la imagen de la desaparición del Estado y la política. James Buchanan, por ejemplo, teórico de la economía de mercado, señala que todo liberal consecuente es, en el límite, necesariamente anarquista ${ }^{1}$. Pues el habitante de la sociedad capitalista, el empresario, el consumidor, el ciudadano, si bien reconoce la necesidad de que haya reglas que regulen los intercambios de todo tipo, también considera que la situación óptima sería que no hubiese ni regulaciones obligatorias ni institutos coercitivos. El modelo ideal de convivencia humana sería, para el liberal, el de la conversación en la que todos pudiéramos participar, alegar al mismo tiempo, y guardar silencio o retirarnos cuando quisiéramos. Este modelo, este pedazo de utopía, estaba ya presente en $\operatorname{Diderot}^{2}$, y transita por infinidad de diseños de mundos deseables, alcanzando incluso, por estos días, al diálogo universal habermasiano, el rortyano y el zapatista. El dispositivo mismo del mercado, eje articulador de la ideología y el engaño neoliberales, centra su poder seductor en la oferta de un sistema de interacciones en el que cada quien pudiese perseguir su propio interés, vivir y comerciar a su aire, sin que hubiese ninguna mano que guiara nada, o si la hubiera se volviera progresivamente invisible. ¿No nace ya el ideal anarquista en la preeminencia moderna dada al individuo? ¿No late en la proclama ilustrada de hacer uso cada uno de la propia razón y en el imperativo kantiano de autonomía, de darnos nosotros mismos la ley?

\footnotetext{
${ }^{1}$ Cfr. Buchanan, James, The Reason of Rules, USA, Cambridge University Press, 2008.

${ }^{2}$ Cfr. De la Fuente Lora, Gerardo, "Diderot, razonar y resonar", en Gutiérrez Castañeda Griselda (compiladora), La revolución francesa doscientos años después, $1^{\text {a }}$ edición, México, Universidad Nacional Autónoma de México, 1991.
} 
Lucio Colletti SeŃala Que MarX se propuso la extinción de toda política y todo Estado. Citémoslo in extenso:

En el marxismo y en el leninismo (aunque puede parecer paradójico destacarlo) falta un análisis serio, articulado, hecho desde dentro, de las instituciones políticas modernas, comenzando por las de la democracia representativa y siguiendo por las relaciones entre los distintos poderes, la función de los partidos, de la burocracia, el papel desempeñado por el Estado en el ciclo económico, etc. Y no sólo falta este análisis, sino incluso el marco en que ubicarlo, el marco en cuyo interior construir una ciencia de la política. Al marxismo le falta este marco porque la teoría marxista de la política y del Estado es, en realidad, la teoría de la "extinción" de ambos. Con otras palabras, el marxismo no ha elaborado una ciencia de la política porque lo que ha hecho ha sido exactamente lo contrario: la teoría de la disolución progresiva de la política y del Estado, la teoría de la abolición (si bien en forma gradual) de la diferencia entre gobernantes y gobernados. ${ }^{3}$

No constituye una paradoja menor el que una propuesta que fue capaz de movilizar movimientos enteros de masas durante más de un siglo, en luchas sostenidas en todos los terrenos, también los políticos, y que con frecuencia se propusieron precisamente tomar el poder, haya sin embargo ocasionado todo eso sin ofrecer ningún asidero teórico mínimamente claro. Lejos de aportar así fuese las líneas primeras de un diseño institucional para el día después a la victoria, lo que se ofreció fueron enunciados extremadamente vagos, a lo sumo, proclamas. Y cuando la claridad alcanzó cotas mayores, el programa se resolvió, a menudo, en elaboraciones fuertemente autoritarias, por decir lo menos, como la dictadura del proletariado. ¿Cómo fue posible, pues, que el pensamiento de Marx subsistiera aún careciendo de una elaboración política propia, en positivo?

\section{III}

SE TRATA AQUí, SIN DUDA, del primer síntoma de una carencia que, habiendo recorrido por lo bajo toda la historia del marxismo, como un fantasma, como un espectro, fue al fin nombrada por Louis Althusser en 1977, a saber, la falta, en Marx, de una teoría del Estado. La enunciación del autor de Pour Marx fue implacable, lejana a toda complacencia. Escuchémoslo:

\footnotetext{
3 Colletti, Lucio, "El problema de la dialéctica", El Viejo Topo, Barcelona, No. 20 (mayo de 1978), p. 8. El número de la revista está dedicado al debate sobre la teoría política en el marxismo.
} 
Tampoco a propósito de la sociedad capitalista y el movimiento obrero, la teoría marxista dice casi nada sobre el Estado, ni sobre la ideología o las ideologías, ni sobre la política, ni sobre las organizaciones de la lucha de clases (estructuras, funcionamiento). Es un "punto ciego" que, indudablemente, demuestra que Marx chocó con determinados límites teóricos, como si se hubiese quedado paralizado por la representación burguesa del Estado, de la política, etc., hasta el punto de no hacer más que reproducirla de una forma negativa (crítica de su carácter jurídico). Punto ciego o zona prohibida, el resultado es el mismo. Y es importante porque la tendencia al comunismo se encuentra como bloqueada (o no se hace conciente de sí) en todo aquello que concierne a estas regiones o a estos problemas. ${ }^{4}$

\section{IV}

DespuÉS DE EXAMINAR Y DENUNCIAR, con detenimiento, las formas en que se desenvuelve el trabajo enajenado en la sociedad capitalista; luego de desvelar el dispositivo a través del cual el objeto producido y la propia actividad productiva se enfrentan al hombre y lo someten; una vez, en fin, que ha puesto de relieve el marco material, concreto, histórico a través del cual acontece la alineación (por contraposición a la perspectiva hegeliana para la cual toda objetivación del espíritu significa un extrañamiento que debe ser superado por la siguiente realización de la idea) Marx deduce el siguiente corolario relativo a las consecuencias políticas de su análisis:

(...) la emancipación de la sociedad de la propiedad privada, etcétera, de la servidumbre, se refleja en la forma política de la emancipación de los trabajadores; no que sea su sola emancipación, sino porque la emancipación de los trabajadores contiene la emancipación universal del hombre: y tiene este contenido porque todo lo que hay de servidumbre en la humanidad está envuelto en la relación del obrero con la producción, y toda relación de servidumbre no es sino una modificación y consecuencia de esa relación. ${ }^{5}$

Sorprende la falta de mediaciones en esta enunciación del joven Marx. En efecto, la emancipación política de los trabajadores se reviste de tan grandes implicaciones no solo libertarias sino incluso metafísicas (pues hablamos aquí de la superación de toda servidumbre humana, nada menos) que parece que la metáfora de tal revulsión como un reflejo de la eliminación de la propiedad privada, resulta demasiado limitada para contener tales torrentes transformadores.

\footnotetext{
${ }^{4}$ Althusser, Louis, "La crisis teórica del marxismo. El problema del Estado", El Viejo Topo, Barcelona, No. 20 (mayo de 1978), p. 5.

5 Marx, Carlos, Manuscritos Económico-Filosóficos de 1844, México, Ediciones de Cultura Popular, 1974, p. 81-82.
} 
HoY LA POLÍTICA EXISTE, sus instituciones y aparatos, sus reglas, incluso sus rutinas y formas de comunicación, pero no hay forma de alcanzarlas, de entrar en ellas, de ejercerlas. La situación recuerda una descripción que realiza Rosalind Krauss ${ }^{6}$ de cierto artista contemporáneo cuya obra consistía en construir espacios habitables pero a los que no podría entrarse por ninguna vía.

Ante la imposibilidad de acabar con la política, las utopías contemporáneas han optado por localizarla en otra dimensión temporal, en un universo paralelo. Y no es que se trate de una hipótesis teórica como en los universos múltiples de ciertas interpretaciones de la mecánica cuántica, pues la política está ahí, podemos percibirla, incluso sufrirla; vaya, podemos remodelarla, reformarla, adecuarla, rediseñarla a cada momento, pero nos es imposible formar parte de su efectuación; hay una membrana, un teorema de imposibilidad entre ella y nosotros.

Por lo demás, la respuesta ciudadana ante esta situación manifiesta una comprensión perfecta de lo que ocurre, pues hombres y mujeres de la calle, en cualquier lugar del mundo dirán, simplemente, "la política no importa".

\section{VI}

LA POLÍTICA SE PERFECCIONA, se reforma. Los cambios constitucionales están a la orden del día. De hecho, los procesos que en América Laina y otras partes del mundo, fueron caracterizados bajo la etiqueta de "transiciones a la democracia", tuvieron como componente central la restructuración y rediseño de las instituciones políticas ${ }^{7}$, tanto en el sentido de las instancias encargadas de canalizar los conflictos, mediarlos y formar consensos, como en la acepción de dispositivos encargados de efectuar las políticas públicas y administrarlas. Como consecuencia de esas transiciones aún recientes, la desinstitucionalización contemporánea exhibe la paradójica faz de ser un proceso de nueva institucionalización.

Probablemente el origen de la paradoja radica en que los devenires transicionales coincidieron en el tiempo con el comienzo del ciclo neoliberal del capitalismo contemporáneo. A la vez que aparentemente se mejoraban las mediaciones entre Estado y sociedad, se dio inicio a un desmantelamiento de las palancas por las que los gobiernos habían podido dar eficacia a sus acciones. El punto central fue la

${ }^{6}$ Krauss, Rosalind, "La escultura en el campo expandido", en Foster Hal (editor), La posmodernidad, 7a edición, Barcelona, Editorial Kairós, 2008, p, 64.

${ }^{7}$ Cfr. Ackerman, John, El mito de la transición democrática, 1ª edición, México, Editorial Planeta, 2015. 
devastación de las herramientas para crear y ejecutar, en cada país, políticas económicas más o menos soberanas.

Autonomización de las bancas centrales; acuerdos de libre comercio e integración que fijaron tasas inamovibles de déficit público, de balanzas comerciales y de cuentas corrientes; establecimiento de tribunales privados para dirimir conflictos comerciales; flexibilidad total para la movilidad de capitales que impuso la competencia entre los estados para atraer inversiones, de por sí especulativas; desmantelamiento, en fin, de las redes de protección social que habían caracterizado al Estado de Bienestar y, con ello, renuncia de la esfera gubernamental a los dispositivos y herramientas que hubieran podido moderar las relaciones entre capital y trabajo.

A la vez que la transición a la democracia parecía privilegiar el ámbito de la política, la neoliberalización vaciaba de operatividad a todas las instituciones, les extraía los resortes performativos y las colocaba como detrás de un aparador en el que pueden ser contempladas pero no usadas, no ejercidas.

Todo ello no tiene nada de casual o contingente, pues el ideal neoliberal consiste en la economización de las relaciones sociales: el mercado y sus mecanismos de decisión racional, constituyen, para esa perspectiva, la mejor opción para tomar decisiones, sin que en ello intervengan veleidades personales o arbitrariedades. Nadie decide, sino las fuerzas impersonales del mercado, o incluso, si se quisiera a pesar de todo buscar un sujeto, el consumidor sería el soberano.

\section{VII}

LA CONJUNCIÓN DE TRANSICIÓN DEMOCRÁTICA y neoliberalismo, trajo consigo una mutación radical en la noción misma del Gobierno, del gobernar.

En la antigüedad "gobierno" se refería a la virtud por la cual se pulsaban y canalizaban las pasiones, se guiaba la propia vida. En la modernidad, a partir de las elaboraciones de lo que los filósofos de los siglos XVII y XVIII (Hobbes, Locke, Rousseau, Montesquieu, Hume, entre muchos otros) que Norberto Bobbio ha agrupado bajo la categoría del "Modelo Iusnaturalista", "gobernar" significó la posibilidad humana de proponerse un sentido y destino para la sociedad, y hacer lo necesario para alcanzarlo. Surgido del Estado de Naturaleza como un ente artificial producto de la voluntad humana, el espacio social podía ser guiado y orientado porque nosotros mismos lo habíamos construido. La sociedad era una máquina creada y por ello

\footnotetext{
${ }^{8}$ Bobbio, Norberto, "El Modelo iusnaturalista", en Bobbio, Norberto y Bovero, Michelangelo, Origen y fundamentos del poder político, $1^{\text {a }}$ edición, México, Grijalbo, 1985.
} 
mismo podíamos cambiarla, El contrato social, la palabra humana, performativa, dio lugar a algo que no existía antes en el mundo, que podía modificarse, ajustarse, e incluso revolucionarse, recurriendo a las mismas fuerzas poderosas que lo habían originado, a saber, nuestra voluntad y nuestra palabra.

El paradigma neoliberal contemporáneo, a diferencia de la filosofía política moderna, parte de la certeza de que la sociedad no es artificial, sino que es natural, y por eso mismo la noción de gobierno en relación a ella tiene que concebirse de otra manera: podemos revelarnos contra las leyes hacendarias, tal vez, pero no podemos hacerlo contra las leyes de la gravedad o de la composición de la materia.

La sociedad es natural, es tan compleja, tan interconectada, sistémica, tan holística, que no hay forma de realizar política que en lo esencial puedan cambiarla ( $y$ el intento de violar las leyes naturales necesariamente será sancionado por la propia naturaleza con crisis terribles como las de los extintos países socialistas o, para el caso, la actual Venezuela). El mercado, mundial, es un mar encrespado en medio del cual los Estados no pueden proponerse otros fines que no sean el simple sobrevivir.

$\mathrm{Y}$ de hecho, todas las medidas propulsadas por el consenso de Washington -presupuestos balanceados, autonomía de los bancos centrales, control de la inflación, etcétera- están pensados como instrumentos para sobrevivir, y su eficacia debería ser evaluada por el cumplimiento de ese objetivo. ¿Qué es un gobierno responsable? El que no se hunde.

\section{VIII}

YA NO SE TRATA, PUES, DE ALCANZAR GRANDES Fines ni de buscar la realización de diseños utópicos de gran escala. Si la política fuese concebida como la lucha en torno a diseños de futuro y al cumplimiento de parámetros universales de justicia, ello no tiene cabida en esta sociedad naturalizada.

Y sin embargo, los partidos, los parlamentos, las instancias de representación, las instituciones que fueron creadas cuando sońamos que podíamos transformar el mundo, siguen ahí y muchas de ellas hacen uso de ingentes recursos públicos. La prensa y los medios de comunicación registran como nunca disensos y debates que parecen intensos y profundos. ¿Pero acerca de qué gira el debate si no es posible transformar ni pensar un destino trascendente para la sociedad naturalizada?

Las instituciones siguen ahí pero la política se ha ido porque se ha dado una disyunción radical entre política y gobierno. Política, lo que ya no hay, es la transformación radical de la sociedad, la revolución. Gobierno, por tanto, ya no es la acción necesaria para llevar a cabo la política. 
Gobernar hoy no quiere decir transformar, proponerse fines y alcanzarlos, sino administrar expectativas.

\section{IX}

El CONFLICTO POSTPOLÍTICO CONSISTE en que un centro, normalmente, traza una línea de expectativas y los demás se adecuan a ella. En México, por ejemplo, hace cuarenta años que no se cumplen los objetivos de política económica que por ley el gobierno debe presentar cada año. ¿Pero si no se cumplen por qué se insiste en presentarlos? Porque no se proponen para cumplirse, sino para que todos los actores de la sociedad alineen sus previsiones, y por tanto su comportamiento, alrededor de la línea de expectativas propuesta por el que gobierna. ¿En qué consiste el conflicto hoy, entre los que antes hubiéramos llamado actores políticos? En la lucha por ser el agente, que proponga la línea de expectativas sobre la que han de girar las conductas de todos los demás. No siempre gobierna el que ocupa el puesto formal de gobernante, pues otros actores pueden obtener fuerza como para ser ellos los que propongan la línea de expectativas. Por ejemplo, en los primeros días de enero de 1994, cuando se levanta en armas el EZLN, el que gobierna no es el que era presidente, Carlos Salinas de Gortari, sino el subcomandante Marcos, pues los inversionistas, los profesores, partidos, sindicalistas, transnacionales, el Fondo Monetario Internacional o el Banco Mundial, no miraban a ver qué es lo que decía Salinas, sino los zapatistas.

Gobernar como administrar expectativas. Se trata de un juego de poses, de gestos desplantes, pero ya no de secuencias de acciones complejas que requieren estabilidad para obtener unos productos específicos ${ }^{9}$. Por eso las instituciones de la política, de la transición democrática, están ahí pero no sirven para nada porque no están para servir. Son instituciones desinstitucionalizadas que están sólo para enmascarar el juego de las expectativas.

Por eso los ciudadanos deseosos de cambiar el mundo no podemos entrar a la política, ni influir en ella. Hay nuevos actores, sí, los que realizan gestos, desplantes y comedias. El Presidente de Guatemala que era comediante televisivo, o Donald Trump, conductor de un Show.

¿Y todo esto es terrible? No, es la realización, por vías inesperadas, de la eliminación de la política por la que tanto nos afanamos antes, marxistas y liberales.

\footnotetext{
${ }^{9}$ He desarrollado ampliamente el tema del gobierno como administración de expectativas en De la Fuente Lora, Gerardo, Amar en el extranjero. Un ensayo sobre la seducción de la economía en las sociedades modernas, $1^{\text {a }}$ edición México, Media Comunicación, 1999.
} 


\section{$\mathrm{X}$}

LA FASE SUPERIOR DE LA DESINSTITUCIONALIZACIÓN de la política como administración de expectativas, es la era del desastre y el Estado de Excepción. Como lo explicó Naomi Klein ${ }^{10}$, vivimos en el capitalismo de la catástrofe: siempre hay una emergencia, un temblor, una bomba en el metro, una urgencia sanitaria, que logran que de pronto aceptemos cosas que en tiempos de normalidad jamás habríamos admitido: reducciones de derechos, expulsiones de migrantes, exacciones presupuestales, etcétera. Porque en la administración de expectativas todo se vale. Hasta la próxima explosión. Las nuevas instituciones giran la noción de gobierno, y se pretenden administradoras del caos.

El problema, tal vez, es que, en efecto, ya nadie gobierna.

Vamos a la deriva y podemos ver a la política ahí, sonriendo, en su aparador.

${ }^{10}$ Klein, Naomi, La doctrina del shock. El auge del capitalismo del desastre, 1a edición, Argentina, Paídós, 2008. 


\section{ReferenCias Bibliográficas}

Ackerman, John. El mito de la transición democrática, $1^{\text {a }}$ edición, México, Editorial Planeta, 2015

Althusser, Louis. «La crisis teórica del marxismo. El problema del Estado», El Viejo Topo, Barcelona, No. 20 (mayo de 1978)

Boвbio, Norberto. «El Modelo iusnaturalista», en Bobbio Norberto y Bovero Michelangelo, Origen y fundamentos del poder político, $1^{\mathrm{a}}$ edición, México, Grijalbo, 1985

Buchanan, James. The Reason of Rules, USA, Cambridge University Press, 2008

Colletti, Lucio. «El problema de la dialéctica», El Viejo Topo, Barcelona, No. 20 (mayo de 1978)

De la Fuente Lora, Gerardo. Amar en el extranjero. Un ensayo sobre la seducción de la economía en las sociedades modernas, $1^{\text {a }}$ edición México, Media Comunicación, 1999

— «Diderot, razonar y resonar», en Griselda Gutiérrez Castañeda (compiladora), La revolución francesa doscientos años después, $1^{\text {a }}$ edición, México, Universidad Nacional Autónoma de México, 1991

Klein, NaOmi. La doctrina del shock. El auge del capitalismo del desastre, $1^{\text {a }}$ edición, Argentina, Paídós, 2008

Krauss, Rosalind. "La escultura en el campo expandido», en Foster Hal (editor), La posmodernidad, 7a edición, Barcelona, Editorial Kairós, 2008

Marx, Carlos. Manuscritos Económico-Filosóficos de 1844, México, Ediciones de Cultura Popular, 1974, p. 81-82

DOI: http://doi.org/10.15366/bp2019.20.002

Bajo Palabra. II Época. No20. Pgs: 39-50 
